\title{
Hyperinsulinism in the Infant of a Diabetic Mother
}

National Cancer Institute

\section{Source}

National Cancer Institute. Hyperinsulinism in the Infant of a Diabetic Mother. NCI

Thesaurus. Code C131835.

Transient hypoglycemia that occurs in the infant of a diabetic mother due to increased postnatal insulin release as a result of in utero exposure to maternal hyperglycemia. 